\title{
Bilişim Teknolojisi Tabanlı Karar Destek Sistemleri İle İplik Üretim Tesislerinde Üretimin Planlanması
} (Araştırma Makalesi)

Planning Production in Yarn Production Facilities with Information

Technology Based Decision Support Systems

Doi: 10.29023/alanyaakademik.705424

Berkant DULKADİR

Dr. (Yerel Yönetimler Yönetimi)

bdulkadir44@hotmail.com

Orcid No: 0000-0002-6074-9473

How to cite this article: Dulkadir, B. (2021). "Bilişim Teknolojisi Tabanlı Karar Destek Sistemleri İle İlik Üretim Tesislerinde Üretimin Planlanması”, Alanya Akademik Bakış, 5(1), Sayfa No. 193-209.

\author{
Anahtar kelimeler: \\ İşletme, \\ Karar Destek Sistemi, \\ Makine, \\ Üretim Planlama, \\ Yönetici \\ Makale Geliş Tarihi: \\ 17.03.2020 \\ Kabul Tarihi: \\ 10.12.2020
}

\begin{abstract}
ÖZET
Işletmeler büyüdükçe işlerin en iyi şekilde ilerlemesi için yapılacak işler karmaşık bir hal almaya başlar. Bu ortamda üretim/hizmet faaliyetlerinin verimli şekilde ilerlemesi için en uygun kararların kisa sürede ve etkin olarak alınması önemlidir. Karmaşık olan tüm verilerin analiz edilerek yöneticilerin karar vermesi için geliştirilmiş bilişim teknolojisi tabanl birçok sistem bulunmakta olup bunlardan birisi ise karar destek sistemleridir. Karar destek sistemleri seçenekler arasından çeşitli analizler ile seçim sunarak en doğru kararın alınması için yöneticilere imkân săglar. Çalışma Gaziantep ilinde iplik üretim faaliyeti gösteren bir işletmede yapılmıştır. Işletmede çalışan tüm makinelerde istasyonlar arasındaki üretim miktarlarının durumlarına göre üretim planının yapılması için karar destek sistemlerinden en etkin şekilde nasıl faydalanılabileceği amaçlanmıştır. Verilerden elde edilen sonuçlara göre çeşitli değerlendirmeler yapılmıştır. Değerlendirmelere bă̆ll olarak tavsiye niteliğindeki konular işletme çalışanları ile paylaşılarak öneriler getirilmiştir. Çalışma iplik üretim tesisleri için bir örnek teşkil edecek olup; diğer sektörler için ise yol gösterici niteliğinde olabilecektir.
\end{abstract}

\section{ABSTRACT}

As businesses grow, things to do to keep things running at their best start to get complicated. In this environment, it is important to make the most appropriate decisions in a short time and effectively for the efficient progress of production / service activities. There are many information technology-based systems developed for managers to make decisions by analyzing all complex data, one of which is decision support systems. Decision support systems provide managers with the opportunity to make the right decision by offering a selection of options with various analyzes. The study was carried out in an enterprise operating in the province of Gaziantep in yarn production. It is aimed how to make the most effective use of decision support systems in order to make a production plan according to the status of production amounts between stations in all machines working 
in the enterprise. Various evaluations were made according to the results obtained from the data. Based on the evaluations, suggestions were made by sharing the advisory issues with the company employees. The study will set an example for yarn production facilities; It can be a guide for other sectors.

\section{GÍRIŞ}

İşletmelerin gelişen Dünya ekonomisi ve teknolojisine ayak uydurmaları için hızlı ve doğru kararı almaları önemli bir gereklilik halini almıştır. Karar verme işlemi iş ile ilgili birçok alternatif arasından uygun seçeneklerin belirlenmesi işlemini kapsamaktadır. Uygun seçeneğin belirlenmesi için ise verilerin doğru bir şekilde analiz edilmesi ve doğru bilgiye ihtiyaç duyulmaktadır. Doğru bilginin elde edilerek analiz edilmesi için ise bilgi sistemlerinin ihtiyaçları en iyi şekilde karşılayacak şekilde geliştirilmesiyle mümkün olmaktadır. Bu işlemler bilişim teknolojisi sistemleri ile daha kolay bir şekilde tasarlanabilmektedir. Bilişim teknolojileri hayatımızın her alanını etkilediği gibi işletmelerin yapılarını da önemli derecede etkilemiş̧tir. Bilişim teknolojisi kavramının birçok unsuru bulunmakta olup bu unsurlarından birisi olan karar destek sistemleri bilgiler arasından değerlendirme yaparak en uygun çözümü uygulama imkânı sağlayan sistem olarak adlandırılabilir. Günümüzdeki rekabet ortamında işletmelerin ellerindeki veriler giderek çoğalmaktadır. İşletmeler bu verileri ilişkili diğer veriler ile gruplandırıp işletme için uygun kararın verilmesi gün geçtikçe önem kazanmaktadır. Karar destek sistemleri verileri bir bütün olarak inceleyip karar verme sürecini geliştirerek karar vericiye olayları daha iyi analiz etmeye teşvik etmek gibi faydası bulunmaktadır.

Karar destek sistemleri günümüzde üretim ve hizmet sektöründe de yaygın olarak kullanılmaktadır. İşletmelerde yöneticilerin karar vermesinde ciddi kolaylıklar ve avantajlar sağlamaktadır. Üretim sektöründe karar destek sistemleri ise üretim planlaması üretim faaliyetlerinin en doğru ve etkin şekilde yürütülebilmesi adına işletme durumuna göre yöneticilerin almış oldukları kararlar toplamı olarak tanımlanabilir. İşletmelerde üretim planlaması yapılırken yöneticiler tecrübelerinden yola çıkıp yaptığı tahminlere bağlı olarak mümkün olduğunca sorunları minimum seviyeye çekecek şekilde karar vermeye çalışırlar. Yöneticilerin işletmelerde üretim planlarını yaparken karar destek sistemlerinden yararlanmaları kendileri ve işletmeleri lehine olacaktır. Karar destek sistemleri yöneticilere işletmeyi küçük bir harita gibi göstererek olayları daha iyi analiz etmesini sağlayacaktır. Çünkü üretimdeki tüm kriterler üretim miktarını olumlu ya da olumsuz etkileyecektir. Karar destek sistemlerinden elde edecekleri bilgilere bağlı olarak yöneticiler daha doğru ve etkin kararlar verebilecektir. Çalışmada işletmedeki tüm makineler arasındaki üretim dengesinin en uygun şekilde nasıl planlanabilmesi için yazılımsal olarak formül oluşturulmaya çalışılmıştır. Yöneticilerin makineler arasındaki üretim miktarının azalığ 1 ya da çokluğu gibi bir problem ile karşılaşmasında karar destek sistemleri ile probleme ilişkin çözüm önerileri sunup geliştirebileceği bir bilgi havuzu oluşturmak amaçlanmıştır. Bunun için ise işletmede bulunan tüm makinelerin üretim ile ilgili tüm teknik verileri alınarak üretimsel hesaplamalar yapılmıştır. Bu üretimsel hesaplamalardan yola çıkılarak zaman, fire, işçilik, malzeme gibi unsurlardan olumsuz yöndeki kayıplar azaltılarak maliyet kaybı önlenilmeye çalışılmıştır. 


\section{KARAR DESTEK SISTTEMLERI}

Hayatın her aşamasında ortaya farklı seçenekler çıkmakta ve bu seçenekler alınan kararları belirlemektedir. Doğru karar vermek bireylerin olduğu kadar işletmelerin de kaderini etkilemektedir (Dönerçark, 2020: 23). Karar destek sistemleri işletme yöneticilerine yarı yapısal olan ya da yapısal olmayan özelliğe sahip sorunların çözümüyle ilgili durumlar da yöneticilerin karar almasına fayda sağlamaktadır. Bu sistemler yöneticinin yerini almaktan ziyade belli bir konuya kolay ve etkili olarak varılmasını destekleyen ve yöneticinin karar almada kolaylık sağlayarak etkililiğini arttıran sistemler olarak tanımlanabilir (Bensghir, 1996:370). Veri tabanı yönetim sistemleri ve yönetim bilgi sistemleri birleştiğinde Karar destek sistemleri ortaya çıkar. Karar destek sistemleri çok sayıda seçim kriterleri olan karmaşık bir bilgi ortamında karar vermeyi desteklemek için kullanılır (Umrerova, 2019: 26). $\mathrm{Bu}$ sistemler karar alıcıları belirli bir konuda desteklemeyi amaçlayan bilgisayar tabanlı bilgi sistemleri olarak da bilinir (Liang vd., 1997:303). Karar destek sistemleri; karar verecek yöneticilere geniş kapsamlı yapılanmamış sorunlara çeşitli alternatifler oluşturulmasında fayda sağlar. Daha sonra oluşturulan bu alternatiflerin etkilerini analiz etmek ve uygulama noktasında uygun çözümleri seçmek için analitik yöntem ve modelleri kullanan karşılıklı etkileşimde bulunan bilgisayar yazılımlarıdır (Watkins vd., 1995:33). Karar destek sistemlerinin işletmeler tarafından kullanılmasıyla, karar vericiler işletmeleri için hangi kararların daha iyi bir sonuç verdiğini görürler ve bu kararları analizleri ile gözlemleyebilirler. İstedikleri raporlara ulaşabilirler, bunlar karar destek sistemin yararlı sonuçlarını ifade eder (Arslan, 2019: 26). Bilgiyi işleyen karar destek sistemleri, olası kararların yeterliliğini tahmin etmektedir. Böylece yönetimsel belirsizliği azaltır ve karar vericilere en iyi olası kararların seçilmesi ve değerlendirilmesinde fayda sağlayabilir (Sindir, 2006:391). Keen ve Morton'a göre karar destek sistemlerinin amaçları şu şekildedir (McLeod, 1995:754).

- Karar vericilere yarı yapısal ve problemlerde yardımcı olma sürecini sağlamak

- Karar vericilerin yargılarının yerine geçmekten çok ona destek sağlama

- Karar vericilerin karar almalarında verimliliği arttırmadan çok etkililiği geliştirmek

Simon'a (1960:75) göre karar vermeyi dört aşamalı olarak tanımlar. Birinci aşama da istihbarat süreci işletmede oluşan problemlerin farkına varılarak teşhis edilmesini sağlamaktadır. İkinci aşama olan tasarım süreci çözüm için gerekli olan problem çözümlerini tasarlamaktadır. Küçük karar destek sistemleri bu aşamada çok ideal olmaktadır. Çünkü küçük modeller üzerinde kısıtlı veriler ile çalışarak hızlıca çalışabilirler. Üçüncü aşama olan seçenek süreci ise alternatifler arasından seçime dayalıdır. Karar verici alternatiflerin oluşturulması için gerekli olan veri ve bilgilere bağlı olarak karar destek sistemlerine ihtiyaç duymaktadır. Yöneticiler karar verme noktasında tüm sonuçlar için karmaşık analitik modeller kullanmak zorundadır. Son aşama olan dördüncü basamak olarak ise çözüm sürecinde ise ortadaki zorluklar, kaynak sıkıntıları ve iyileştirmeyi sağlayan bir raporlama sistemi oluşturulabilir (Özer ve Kuşlu, 2012:397).

Kurumsal işletmelerin yaptıkları bilimsel açılım ve tasarımlara bağlı olarak, çalışmaların sonuçlarının önemi açısından stratejik, taktiksel, operasyonel ve yönetsel olarak sınıflandırılan karar alma şekilleri, yapıları açısından da yapısal, yarı yapısal ve yapısal olmayan kararlar olarak üç şekilde sınıflandırılır (Alagöz vd., 2013:32). Yapısal kararlar; Kararın her aşaması için tanımlanmış konunun yapısına göre geliştirilmiş bir kurallar 
sıralaması söz konusudur. Bu tip karara örnek olarak, işgörenin performansı belirli bir değerin altına düştüğünde bu düşüşün nedeni incelenmesi için yöneticiye bilgi aktarımı kararı örnek verilebilir. Genellikle bu kararları orta düzey yöneticiler almakta olup bunlar yapısal kararlar olarak adlandırılırlar. Yarı yapısal kararlar ise; Karar durumlarının çoğu yarı yapılanmış karar özelliği taşır. Yarı yapılanmış karar durumlarında, sorunlara farklı bakış açılarıyla belirli işlem dizileri uygulanabilir. Karar vermek için sorunun diğer yönleri tesadüfî nedenlere ve ilişkilere bağlı olmasından dolayı, devreye yöneticinin girmesi gerekmektedir. Yapısal olmayan kararlar ise; Karar aşamalarının tamamında belirsizlik durumunun söz konusu olmasıdır. Bu sorunlar genellikle bir kerelik olmak üzere karşılaşılan ve çok iyi bir şekilde tanımlanmayan sorunlar olup; Karar aşamalarının tümü yapısallıktan uzaktır. Karar alırken herhangi bir prosedürün takip edilmesi gibi bir zorunluluk olmayıp, yöneticinin kendi sezgilerini kullanma ihtiyacı ortaya çıkarır. Yeni ürün ve pazar kararları, işletmenin imajının değiştirilmesi gibi durumlar bu kararlara örnek olarak verilebilir.

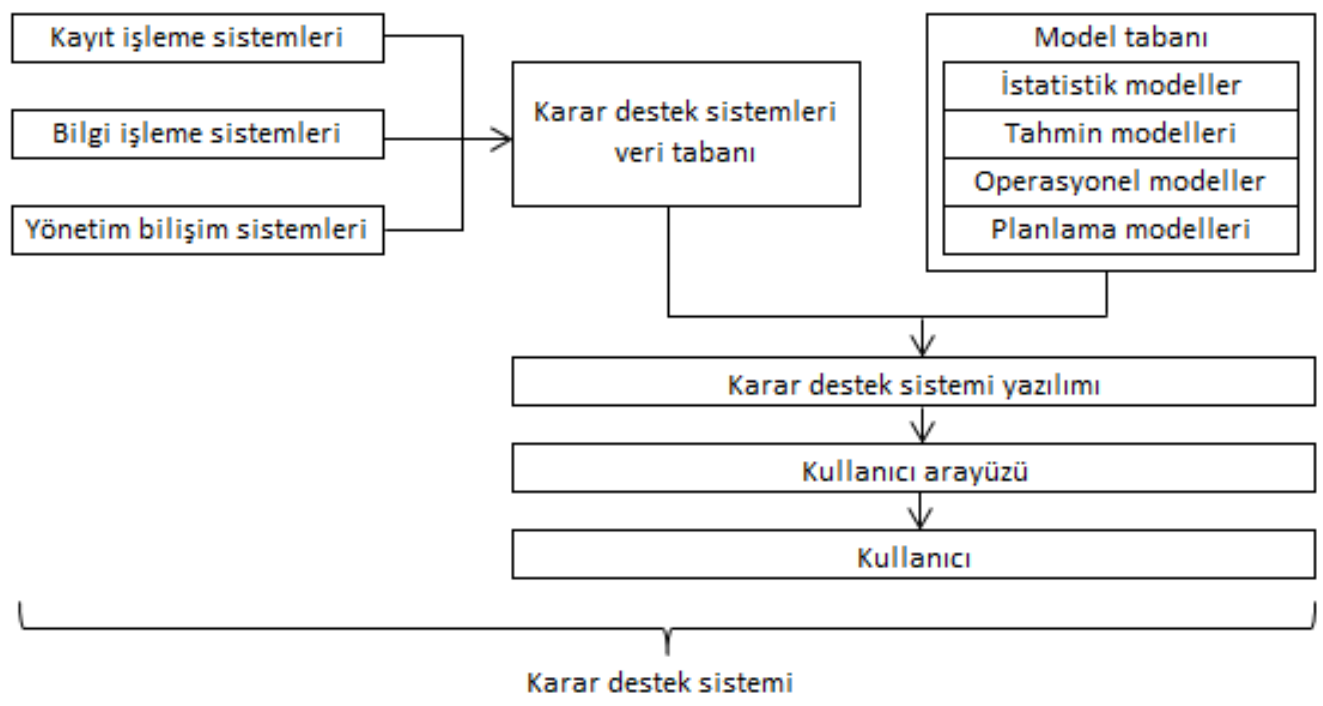

(Gökşen vd., 2015:57).

\section{Şekil 1. Karar Destek Sistemi Bileşenleri}

Teknolojideki gelişmeler; veri depoları, online işleme uygulamaları karar destek sistemlerinin büyük miktarda verileri kısa sürelerde işlemesini sağlayacak bir altyapı oluşturmuşlardır. Veri odaklı karar destek sistemleri büyük miktarda veriler üzerinden anlamlı veri bağlantılarına ulaşarak önemli bilgileri tanımlanan modeller çerçevesinde kullanıcılara sunarak ve daha uygun kararlara altyapı teşkil edebilmektedirler (Laudon ve Laudon; 2018: 48:50).

\section{3. ÜRETIM VE PLANLANMASI}

İşletmemelerin amacı ihtiyaçları karşılamak amacıyla ürün/hizmet faaliyetlerini yürüterek pazarlamasını yapmaktır. Bu faaliyetlerin yerine getirilmesi için üretim unsurlarının sürekli olarak kullanılması gerekmektedir. Böylece bir işletme için gerekli olan binalar, makineler, teknik unsurlar, enerji, işgücü, hammadde ve çeşitli türden hizmet çalışmaları gerekli olur. Gerekli olan bu unsurlar üretimin amaçlarına göre işletmenin değişik bölümlerine yerleştirilir. 
Teorik olarak irdelendiğinde, üretim çalışmaları tek bir işlemden başlayarak tümevarım işlemidir. Bu tümevarım da var olan tüm üretim unsurları, ürünleri müşteriye satışa hazır hale getirmek için en sondaki işleme kadar birbirleriyle etkileşimsel olarak işbirliği içerisinde hareket etmektedirler (Demirdöğen, Güzel, 2009:44). Üretim planlama işletmenin maliyetlerini düşürmek ve müşteri memnuniyetini sağlamak için üretim kaynaklarının kullanım ve tahsisini en uygun şekilde sağlayan bir faaliyet olup; üretim planlama kararları, işgücü seviyesinin takibi, üretim kararlarının sıralanması gibi kararları içerir (Graves, 1999:1).

Üretim planlamasının amacı, yakın gelecekteki dalgalanan veya belirsizlik gösteren taleplerin karşılanması için tüm ürün kategorilerinde üretim seviyelerini belirlemek ve kiralama, işten çıkarma, fazla mesai, yok satma, fason üretim, stok seviyesi gibi hususlarda karar ve politikaların oluşturulması ve böylece kullanılacak uygun kaynakların belirlenmesidir (Paksoy, Atak, 2003:28). Üretim planlamanın odak noktası gelen siparişlerin düzenlenmesidir ve ortalama cevap süresi, ortalama sipariş gecikmesi gibi performans ölçütleri sipariş odaklıdır (Soman vd., 2004:223).

İşletmelerde üretim performansının en iyi noktaya ulaşmasını sağlamak için en önemli araçlardan birisi, müşteri ve pazar isteklerine uygun ürünler sunmak amaciyla mevcut kapasiteden en yüksek faydayı sağlayarak, en fazla karı getirecek minimum maliyetle üretim planlarının hazırlanmasıdır. Teknolojik gelişmelere bağlı olarak üretim sistemlerinin gelişmesi de işletmelerde üretim planlama fonksiyonunun önemi zaman geçtikçe artmaktadır. Modern bir işletmede; departmanlar arasındaki koordinasyonun zorluğu, işletmeler arası ilişkilerin gelişmesi, diğer işletmelerle kalite fiyat hizmetteki rekabet durumu, müşteri tercihlerindeki değişmeler, diğer malzeme, hammadde vb. kayıplarının minimum düzeye indirilerek minimum maliyetlerde çalışılması gibi faktörler üretim planlama fonksiyonunu önemini göstermektedir. Üretim planlama, işletmenin üretim faaliyetlerinin istenilen miktar ve kalitede sağlayacak şekilde geleceği zaman dilimlerine bölmek ve işleri önceliğine göre yerleştirmek konularında karar verme süreci olarak tanımlanabilir. Üretim planlama konusunda ürün yöneticilerine önemli bir görev düşmektedir. İşin en zorlu kısmı üretimin planlanması için mevcut ürünlere hangi periyotlarda hangi miktarlarda ihtiyaç duyulacağını tespit etmektir. Buna bağlı olarak üretime etki eden tüm kriterleri de göz önüne alarak üretilecek ürünlerin tedarikçilerden-tüketicilere, sürecin etkili ve doğru bir şekilde yönetilmesi gerekmektedir (Demir ve Dinçer, 2020: 2). Üretim planlama sürecinin çıktıları, her üründen zamanlarına göre üretilecek miktarlar, esnek alternatif üretim süreçleri, her istasyonda hangi ürünün ne zaman üretileceği kararları, stok düzeyleri, bekleyen sipariş miktarları, fason üretime verilen miktarlar, fazla mesai ve kullanılmayan kapasite durumları, bu düzeydeki değişmeler, malzeme, hammadde, tedarik programı vb. gereksinimler gibi kararlardır (Şen ve Cenkci, 2009:2).

Üretim planları uzun, orta ve kısa vadeli olmak üzere üç şekilde hazırlanmaktadır. Uzun vadeli planlar genellikle 5 yıl ve daha fazlası için kapasite, yerleşim ya da üretim hattı gibi kendisinden kısa planları etkileyecek olan kararları verirken kullanılmaktadır. Üretime başlayabilmek için gereken iş gücü, malzeme, ekipman, üretim tipi, tezgâh yerleşimleri gibi temel unsurların planlandığı dönemdir. Orta vadeli planlarda ise bir üretim tesisinin 1 ile 5 yıl arasındaki üretim ve ihtiyaç miktarları planlanır. Bu dönemde çıktının miktarı kadar girdiyi etkileyen faktörler de planlamada önem arz etmektedir. Stok düzeyi, çalışma saatleri, işçi alımları ya da çıkarılması gibi kararlarla maliyeti düşürmeye, üretimi arttırmaya yönelik 
planlamalar yapılır. K1sa vadeli üretim planları bir yıldan kısa süreli planlamaları kapsamaktadır. Üretim programları da denilen bu planlama türünde uzun ve orta vadede ulaşılması istenen hedefler için kısa süreli plan ve programlar yapılır (Karaöz, 2014:12).

\section{ARAŞTIRMANIN MATERYAL VE YÖNTEMI}

Araştırma Gaziantep ilinde tekstil sektörünün bir kolu olan iplik alanında yeni kurulmuş olan bir işletmede yapılmıştır. Çalışmada Bilişim teknolojisi tabanlı karar destek sistemleri ile iplik üretiminin en verimli şekilde planlanması amaçlanmıştır. Yöneticilerin üretim planlaması konusunda karar vermesinde etkililiğini artırmak amacıyla üretim akışı izlenerek çeşitli hesaplamalar yapılarak yazılımsal formül oluşturulmuştur. Araştırma için iplik sektörünün seçilme sebebi ise ülkemizin tekstil sektöründe öncü ülkeler arasında olması ve araştırmadan çıkacak sonuçların diğer sektörler için de örnek teşkil edebilecek olmasıdır. Karar destek sistemlerinden ve Office programlarından Microsoft Excel kullanılarak yazılımsal hesaplamalar ve Makro kullanımıyla kayıt altına alma işlemi yapılmıştır. Microsoft Excel kullanıcıların tablo çizmesi ve detaylı yazılımsal formülsel hesaplamaları yapması için formül kolaylığı sağlayan gerekirse bunu grafiklere aktaran bir bilişim sistemdir. İplik üretimi için Ring (Karde, Penye) ve Open-End iplik sistemleri mevcut olup araştırma Ring iplik üretim tesisleri Karde üretim sistemi üzerinde yapılmıştır. Karde iplik üretim sistemi makine parkı ise Harman-Hallaç, Tarak, CerI Pasaj. CerII. Pasaj, CerII. Pasaj, Fitil, Ring, Bobin makineleri ve ambalaj bölümlerinden oluşmaktadır. Elyafın kabartılarak açılması, yabancı maddelerden temizlenmesi, taranarak şerit haline gelmesi ve istenilen inceliğe çekilmesi, büküm verilerek iplik haline dönüştürülmesine işlemine iplik üretim sistemi denir. Harman hallaç bölümünde pamuk açılır, temizlenir ve harmanlanır. Tarak bölümünde; pamuk tek lif haline getirilerek taranır, kısa lifleri nepsleri (taranmamış elyaf) ayırarak şerit haline getirip kovalara doldurur. Cer bölümünde elyafların paralelleşmesi sağlanarak dublaj (birleştirme) ile harmanlanır ve bu işlem CerII. Pasaj ünitesinde tekrarlanmaktadır. Fitil ünitesinde; şerit inceltilerek büküm verilir ve makaralara sarılır. Ring ünitesinde de fitil inceltme, büküm verme ve masuralara sarma işlemleri yapılır. Ring iplik makinesinde ise fitilden gelen şeritler daha da inceltilerek iplik halini alır. Bobin ünitesinde ise iplikler belirli ağırlıklarda bobin haline getirilmekte ve aktarma esnasında iplik üzerindeki hatalar kesilerek ayrılır. Çünkü ring makinesinde üretilen iplikler 50-80 gr'lık masuralar halindedir ve iplikleri bu şekilde müşterilere gönderilmesi üretim tekniği olarak mümkün değildir. Son olarak ambalajlama kapsamaktadır. Üretim programları da denilen bu planlama türünde uzun ve orta vadede ulaşılması istenen hedefler için kısa süreli plan ve programlar yapılır (Karaöz, 2014:12). 


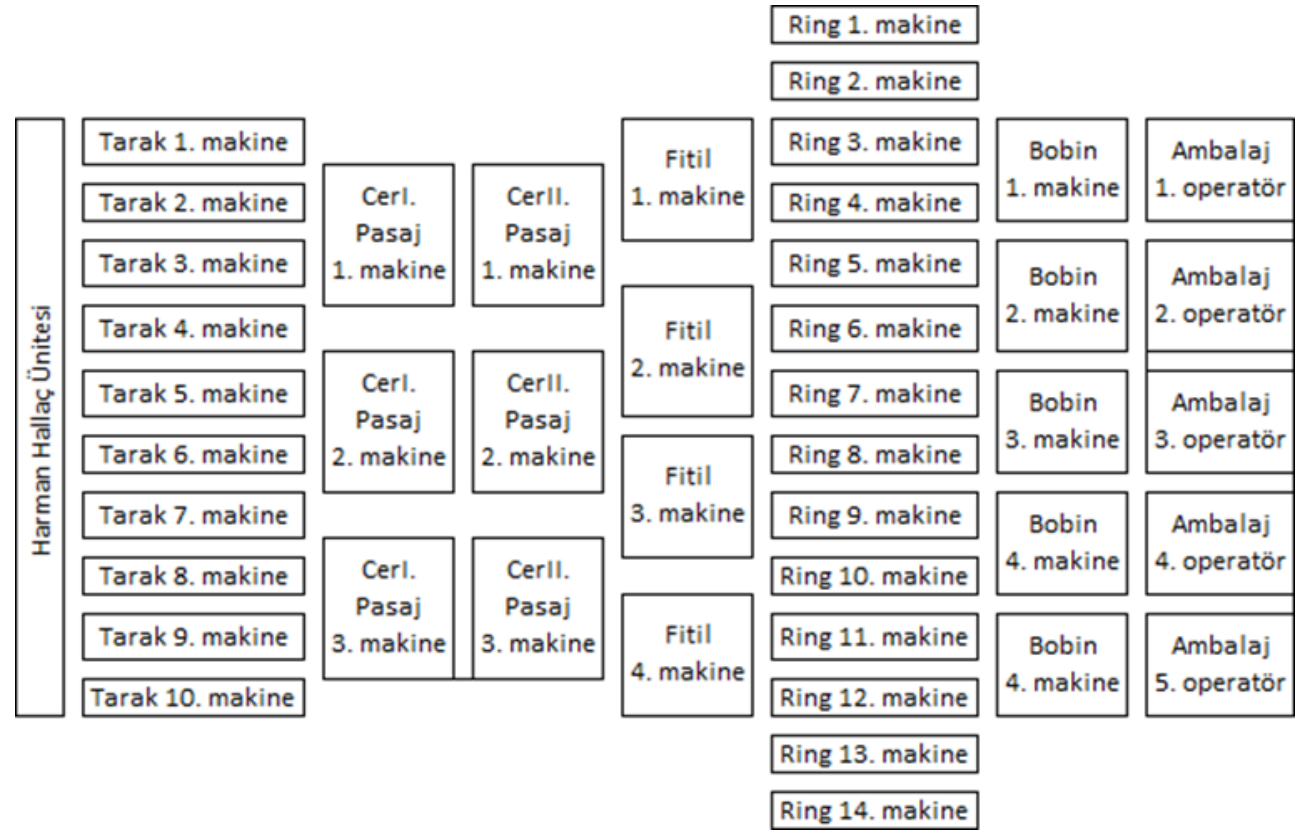

Şekil 2. İşsetmenin Makine Parkı Planı

İşletmenin makine parkı ve adetleri işletme kapasitesine göre kuruluşta dizayn edilmiş olup şu şekildedir. Makineler arasında pamuk beslemesi üretim kapasitesine göre devir, ürün numarası ve diğer teknik verilere göre ayarlanmıştır. Harman- Hallaç ünitesi, 10 adet tarak makinesi, 3 adet CerI. pasaj makinesi, 3 adet CerII. pasaj makinesi, 4 adet fitil makinesi, 14 adet Ring makinesi, 5 adet bobin makinesi ve ambalaj bölümünde 5 operatör bulunmaktadır. Şekil 2' de işletmenin makine parkı planı görülmektedir.

Yeni kurulan iplik işletmesinde randıman sorunu kaynaklı makineler arasında üretim planlaması sorunu tespit edilmiştir. Randıman sorunu kaynaklı yöneticilerin yaptığı üretim planlamasının düzgün şekilde ilerlememesinden dolayı konu bilişim sistemleri tabanlı karar destek sistemleri ile çözülmeye çalışılmıştır. İşletmenin 24 saat' lik üretimi dikkate alınarak araştırma yapılmıştır. Karar destek sistemi olan Microsoft Excel kullanılarak her makinenin üretimi farklı şekilde yazılımsal olarak formülüze edilerek ayrı ayrı hesaplanmıştır. İşletmenin referans üretim miktarı işletmedeki makine ve diğer teknik verilere bağlı olarak işletme yöneticileri tarafından belirlenmiştir. Yapılan hesaplarda yazılımsal formüller matematiksel ifadeler ile açıklanmaya çalışılmış ve tablolar ile açıklanmaya çalışılmıştır. Her makine için ayrı bir tablo oluşturulmuştur. Her makine için ayrı ayrı olarak kendinden bir önceki makinenin yarı mamul tedariki yani besleme durumu için "üretim artırılsın", "üretim aynı kalsın" şeklinde karar önerilerinde bulunacak şekilde yazılımsal olarak formülüze edilmiştir. Üretim esnasında bakım, arıza vb. nedenlerden kaynaklı duruşlar olmuştur. Formüller oluşturulurken makine bazında ilgili üretim hesaplama teknikleri ve teknik veriler dikkate alınmıştır. Üretim planlamasının seyri için karar değişikliği önerisi ise yine aynı şekilde formülüze edilmiştir. Böylece yöneticiler tarafından üretim planlaması ile ilgili geleceğe yönelik kararlar alınması konusunda bu bilgilerden yararlanılabilecektir. Çalışma 
işletmenin sadece bir bölümü için değil tamamı için yapılmış olup işletmenin ana üretim bölgesi Ring makineleridir. Araştırma sonuçları dikkate alınarak oluşturulan üretim planlaması kararları işletmenin daha iyi bir noktaya gelebilmesi için nasıl ve neler yapılması gerektiği incelenmiştir.

\section{ARAȘTIRMANIN BULGULARI}

İplik işletmesindeki üretim miktarının tespiti için her makine ayrı ayrı yazılımsal olarak formüllendirilerek tablolar ile açıklanmaya çalışılmıştır. Bu yöntem ile makineler arasındaki yarı mamul yetersizliğinden kaynaklı üretim planlaması ve yönetimi konusunda yöneticilere karar noktasında yardımcı olunmaya çalışılmıştır. Üretimin ilk aşaması olan Harman-Hallaç ünitesinde hammadde beslemesi sürekli olarak yapılmaktadır. Bir sonraki kısım olan tarak makinesinin 24 saat içinde gerçekleşen üretim hesaplamaları Tablo 1' de diğer makinelerin üretim hesaplamaları ise devamındaki tablolarda verilmiştir. Harman-Hallaç ünitesi için üretim değişikliği karar önerisi yöneticilerin üretimi planlaması açısından karar vermelerine yardımcı olmak için tablolaştırılarak detaylandırılmıştır.

Karar destek sistemi ile kurulan bu sistem işletme faaliyetlerine devam ettiği sürece tekrarlanacağı için yazılım sistemiyle kayıt altına alınarak yöneticilerin işlerini kolaylaştırmak mümkündür. İlgili işlemler ise makro yazılım sistemiyle kayıt edilebilmektedir. Makro kullanımı ise sürekli kullanabileceğiniz sıklıktaki işlemleri bir bütün olarak kayıt altına almaktadır. Araştırması yapılan işlemler ise sürekli takip edileceği ve tekrarlanacağı için aşağıda verilmiş olan yazılım oluşturularak kayıt altına alınmıştır.

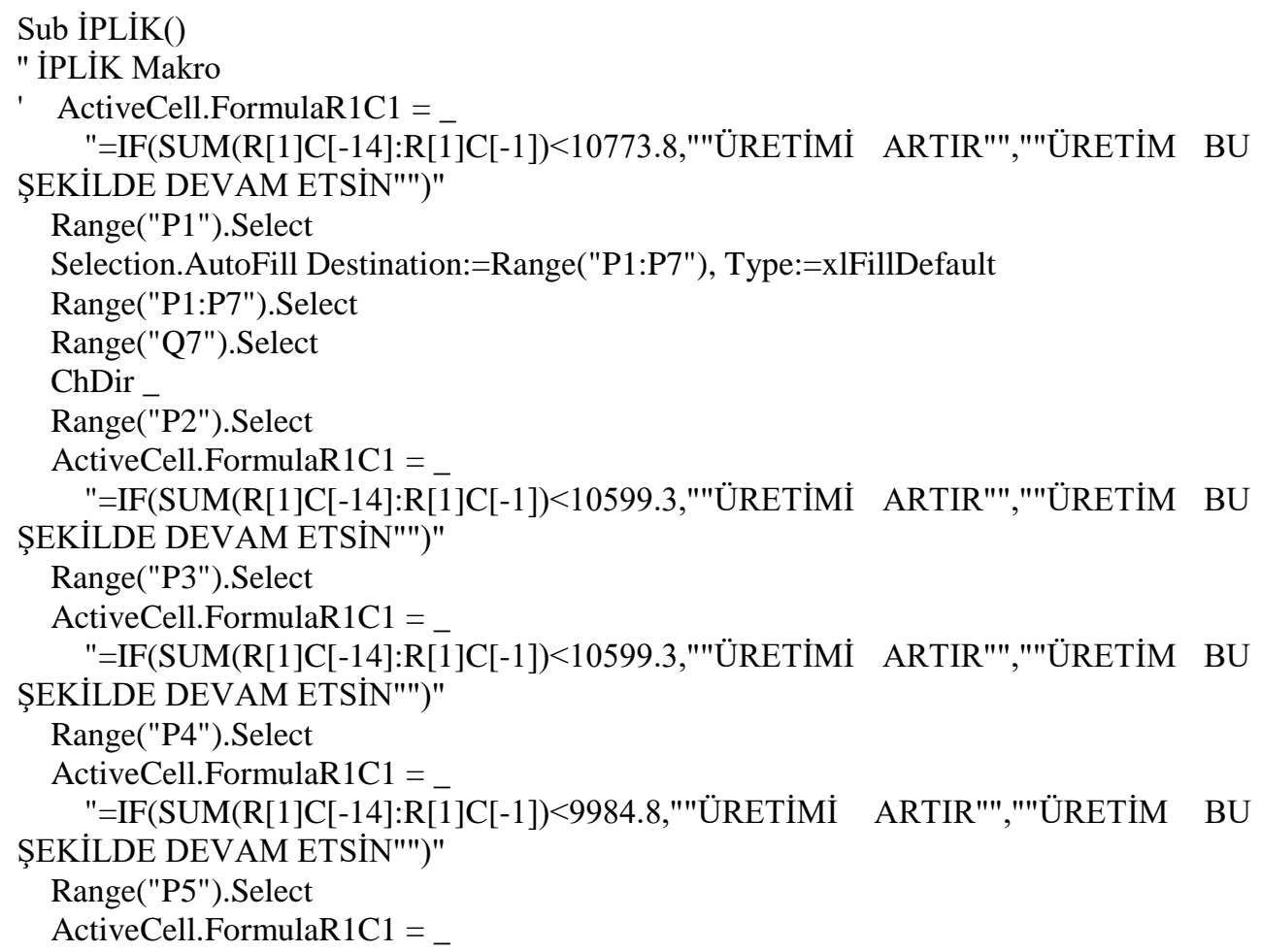


"=IF(SUM(R[1]C[-14]:R[1]C[-1])<9800.3,"'ÜRETIMII ARTIR"",,"'ÜRETİM BU ŞEKİLDE DEVAM ETSIN"'")"

Range("P6").Select

ActiveCell.FormulaR1C1 =

"=IF(SUM(R[1]C[-14]:R[1]C[-1])<9426.6,"'ÜRETIMII ARTIR"","'"ÜRETIM BU ŞEKILDE DEVAM ETSIN"'")"

Range("P7").Select

ActiveCell.FormulaR1C1 = "=IF(SUM(R[1]C[-14]:R[1]C[-1])<9570,"'"ÜRETIMII

ŞEKILLDE DEVAM ETSIN"'")"

Range("P8").Select

End Sub

İlgili makro yazılımından sonra işletmenin diğer tüm teknik verileri ve fiili gerçekleşen işlemleri tablolar ile detaylandırılarak aşağıdaki gibi gösterilmiştir.

Tablo 1. Tarak Makinesi Üretim Verileri

\begin{tabular}{|c|c|c|c|c|c|}
\hline Makine Bilgileri & Tarak 1 & Tarak 2 & Tarak 3 & Tarak 4 & Tarak 5 \\
\hline Ne & 0,120 & 0,120 & 0,120 & 0,120 & 0,120 \\
\hline Devir(m/dk) & 160 & 160 & 160 & 160 & 160 \\
\hline Randıman & 93 & 91 & 95 & 94 & 92 \\
\hline Üretim Miktarı (kg) & $1.054,7$ & $1.032,0$ & $1.077,4$ & $1.066,0$ & $1.043,4$ \\
\hline Makine Bilgileri & Tarak 6 & Tarak 7 & Tarak 8 & Tarak 9 & Tarak 10 \\
\hline Ne & 0,120 & 0,120 & 0,120 & 0,120 & 0,120 \\
\hline Devir(m/dk) & 160 & 160 & 160 & 160 & 160 \\
\hline Randıman & 94 & 94 & 95 & 90 & 93 \\
\hline Üretim Miktarı (kg) & $1.066,0$ & $1.066,0$ & $1.077,4$ & $1.020,7$ & $1.054,7$ \\
\hline
\end{tabular}

Tablo 1' de görüldüğü üzere Ne şerit (iplik oluşması için kalın pamuk yığını) numarasını, devir makinenin dakika' da ki dönüş hızına bağlı olarak üretilen şeritin metre miktarını, randıman ise gerçekleşen verimlilik oranını (olması gereken randıman oranı \%95), üretim miktarı ise fiili üretim miktarını ifade etmektedir. Tabloda verilen teknik değerler işletmenin çalışması esnasında ki makinelerin verisidir. Gerçekleşen üretim miktarı ise Microsoft Excel yardımıyla hesaplanmış olup Tarak 1 sütunu aşağıya doğru B2 (0,120) - B3 (160) -B4 (91) gerçekleşen randıman - B5 $(1054,7)$ hücresel olarak sınıflandırılacak olursa B5 olan hücre yani üretim miktarı bu şekilde $=((((B 3 * 60) /(1,693 * B 2)) *(B 4 / 100)) / 1000) * 24$ formülüze edilerek 1054,7 kg üretim miktarı bulunmuştur. Diğer üretim hesaplamaları hücresel olarak sınıflandırılarak üretim miktarı bu şekilde hesaplanmıştır.

Tarak makineleri direk Harman-Hallaç ünitesinden beslendiği için tüm makinelerin toplam üretimine bakarak üretim planlamasının yapılması için Microsoft Excel yardımıyla hesaplanmış olan ve =EĞER(TOPLA(B5:M5)<10773,8;"Üretimi Artır"; "Üretim Bu Şekilde Devam Etsin") bu şekilde formülüze edilen karar destek sistemiyle yöneticilerin karar 
vermelerine yardımc olacaktır. 10773,8 rakamı referans randıman oranı \%95 baz alınarak belirlenmiştir. 10558,3<10773,8 olduğundan üretimin artırılması yönünde karar alınabilir.

Tablo 2. Cer I. Pasaj Makinesi Üretim Verileri

\begin{tabular}{|c|c|c|c|}
\hline Makine Bilgileri & $\begin{array}{c}\text { Cer 1 } \\
\text { (I.Pasaj) }\end{array}$ & $\begin{array}{c}\text { Cer 2 } \\
\text { (I.Pasaj) }\end{array}$ & $\begin{array}{c}\text { Cer 3 } \\
\text { (I.Pasaj) }\end{array}$ \\
\hline Ne & 0,130 & 0,130 & 0,130 \\
\hline Devir(m/dk) & 675 & 675 & 675 \\
\hline Randıman & 78 & 76 & 77 \\
\hline Üretim Miktarı (kg) & $3.444,8$ & $3.356,4$ & $3.400,6$ \\
\hline
\end{tabular}

Tablo 2' de görüldüğü Ne şerit (iplik oluşması için kalın pamuk yığını) numarasını, devir makinenin dakika' da ki dönüş hızına bağlı olarak üretilen şeritin metre miktarını, randıman ise gerçekleşen verimlilik oranını (olması gereken randıman oranı \%80), üretim miktarı ise fiili üretim miktarını göstermektedir. Tabloda verilen teknik değerler işletmenin çalışması esnasında ki makinelerin verisidir. Gerçekleşen üretim miktarı ise Microsoft Excel yardımıyla hesaplanmış olup Cer 1 (I.Pasaj) sütunu aşağıya doğru B2 (0,130) - B3 (675) - B4 (74) gerçekleşen randıman - B5 $(3448,8)$ hücresel olarak sınıflandırılacak olursa B5 olan hücre yani üretim miktarı bu şekilde $=((((B 4 * 60) /(1,693 * B 3)) *(B 5 / 100)) / 1000) * 24$ formülüze edilerek $3444,8 \mathrm{~kg}$ üretim miktarı bulunmuştur. Diğer üretim hesaplamaları hücresel olarak sınıflandırılarak üretim miktarı bu şekilde hesaplanmıştır.

Cer I. Pasaj makineleri direk Tarak ünitesinden beslendiği için tüm makinelerin toplam üretimine bakarak üretim planlamasının yapılması için Microsoft Excel yardımıyla hesaplanmış olan ve =EĞER(B5:D5)<10599,3;"Üretimi Artır"; "Üretim Bu Şekilde Devam Etsin") bu şekilde formülüze edilen karar destek sistemiyle yöneticilerin karar vermelerine yardımcı olacaktır. 10599,3 rakamı referans randıman oranı \%80 baz alınarak belirlenmiştir. 10201,8<10599,3 olduğundan üretimin artırılması yönünde karar alınabilir.

Tablo 3. Cer II. Pasaj Makinesi Üretim Verileri

\begin{tabular}{|c|c|c|c|}
\hline Makine Bilgileri & $\begin{array}{c}\text { Cer 1 } \\
\text { (II.Pasaj) }\end{array}$ & $\begin{array}{c}\text { Cer 2 } \\
\text { (II.Pasaj) }\end{array}$ & $\begin{array}{c}\text { Cer 3 } \\
\text { (II.Pasaj) }\end{array}$ \\
\hline Ne & 0.130 & 0.130 & 0.130 \\
\hline Devir(m/dk) & 675 & 675 & 675 \\
\hline Randıman & 76 & 77 & 75 \\
\hline Üretim Miktarı (kg) & 3356.4 & 3400.6 & 3312,3 \\
\hline
\end{tabular}

Tablo 3' de görüldüğü üzere Ne şerit (iplik oluşması için kalın pamuk yığını) numarasını, devir makinenin dakika' da ki dönüş hızına bağlı olarak üretilen şeritin metre miktarını, randıman ise gerçekleşen verimlilik oranını (olması gereken randıman oranı \%80), üretim miktarı ise fiili üretim miktarını göstermektedir. Tabloda verilen teknik değerler işletmenin çalışması esnasında ki makinelerin verisidir. Gerçekleşen üretim miktarı ise Microsoft Excel yardımıyla hesaplanmış olup Cer 1 (II.Pasaj) sütunu aşağıya doğru B2 (0.130) - B3 (675) B4 (73) gerçekleşen randıman - B5 (3356.4) hücresel olarak sınıflandırılacak olursa B5 olan hücre yani üretim miktarı bu şekilde $=(((\mathrm{B} 4 * 60) /(1,693 * \mathrm{~B} 3)) *(\mathrm{~B} 5 / 100)) / 1000) * 24$ 
formülüze edilerek $3356,4 \mathrm{~kg}$ üretim miktarı bulunmuştur. Diğer üretim hesaplamaları hücresel olarak sınıflandırılarak üretim miktarı bu şekilde hesaplanmıştır.

Cer II. Pasaj makineleri direk Cer I. Pasaj ünitesinden beslendiği için tüm makinelerin toplam üretimine bakarak üretim planlamasının yapılması için Microsoft Excel yardımıyla hesaplanmış olan ve =EĞER(TOPLA(B5:D5)<10599,3;"Üretimi Artır"; "Üretim Bu Şekilde Devam Etsin") bu şekilde formülüze edilen karar destek sistemiyle yöneticilerin karar vermelerine yardımc olacaktır. 10599,3 rakamı referans randıman oranı \%80 baz alınarak belirlenmiştir. 10069,3<10599,3 olduğundan üretimin artırılması yönünde karar alınabilir.

Tablo 4. Fitil Makinesi Üretim Verileri

\begin{tabular}{|c|c|c|c|c|}
\hline Makine Bilgileri & Fitil 1 & Fitil 2 & Fitil 3 & Fitil 4 \\
\hline Ne & 0.8 & 0.8 & 0.8 & 0.8 \\
\hline Büküm (T/M) & 46 & 46 & 46 & 46 \\
\hline Devir(m/dk) & 1200 & 1200 & 1200 & 1200 \\
\hline Randıman & 75 & 74 & 74 & 73 \\
\hline Üretim Miktarı (kg) & 2.496 .2 & 2.462 .9 & 2.462 .9 & 2.429 .6 \\
\hline
\end{tabular}

Tablo 4' de görüldüğü üzere Büküm(T/M) makinede akan şerite bir metre boyunca Atılacak tur sayısınıi Ne şerit (iplik oluşması için kalın pamuk yığını) numarasını, devir makinenin dakika' da ki dönüş hızına bağlı olarak üretilen şeritin metre miktarını, randıman ise gerçekleşen verimlilik oranını (olması gereken randıman oranı \% 75 ), üretim miktarı ise fiili üretim miktarını göstermektedir. Tabloda verilen teknik değerler işletmenin çalışması esnasında ki makinelerin verisidir. Gerçekleşen üretim miktarı ise Microsoft Excel yardımıyla hesaplanmış olup Fitil 1 sütunu aşağıya doğru B2 (0,8) - B3 (46) -B4 (1200) - B5 (75) gerçekleşen randıman - B6 $(2496,2)$ hücresel olarak sınıflandırılacak olursa B6 olan hücre yani üretim miktarı bu şekilde $=(120 *((\mathrm{~B} 5 / \mathrm{B} 4) /(1,693 * \mathrm{~B} 3)) *(\mathrm{~B} 6 / 100) * 60 * 24) / 1000$ formülüze edilerek 2496,2 $\mathrm{kg}$ üretim miktarı bulunmuştur. Diğer üretim hesaplamaları hücresel olarak sınıflandırılarak üretim miktarı bu şekilde hesaplanmıştır.

Fitil makineleri direk Cer II. Pasaj ünitesinden beslendiği için tüm makinelerin toplam üretimine bakarak üretim planlamasının yapılması için Microsoft Excel yardımıyla hesaplanmış olan ve =EĞER(TOPLA(B5:E5)<9984,8;"Üretimi Artır"; "Üretim Bu Şekilde Devam Etsin") bu şekilde formülüze edilen karar destek sistemiyle yöneticilerin karar vermelerine yardımc olacaktır. 9984,8 rakamı referans randıman oranı \%75 baz alınarak belirlenmiştir. 9851,7<9984,8 olduğundan üretimin artırılması yönünde karar alınabilir.

Tablo 5. Ring Makinesi Üretim Verileri

\begin{tabular}{|c|c|c|c|c|c|c|c|}
\hline Makine Bilgileri & Ring 1 & Ring 2 & Ring 3 & Ring 4 & Ring 5 & Ring 4 & Ring 5 \\
\hline Ne & 20 & 20 & 20 & 20 & 20 & 20 & 20 \\
\hline Büküm (T/M) & 678 & 678 & 678 & 678 & 678 & 678 & 678 \\
\hline Devir(m/dk) & 10.000 & 10.000 & 10.000 & 10.000 & 10.000 & 10.000 & 10.000 \\
\hline Randıman & 90 & 89 & 88 & 87 & 91 & 89 & 90 \\
\hline
\end{tabular}


DULKADİR

\begin{tabular}{|c|c|c|c|c|c|c|c|}
\hline Üretim Miktarı (kg) & 677.4 & 669.9 & 662.4 & 654.9 & 685.0 & 669.9 & 677.4 \\
\hline Makine Bilgileri & Ring 8 & Ring 9 & Ring 10 & Ring 11 & Ring 12 & Ring 13 & Ring 14 \\
\hline Ne & 20 & 20 & 20 & 20 & 20 & 20 & 20 \\
\hline Büküm (T/M) & 678 & 678 & 678 & 678 & 678 & 678 & 678 \\
\hline Devir(m/dk) & 10000 & 10000 & 10000 & 10000 & 10000 & 10000 & 10000 \\
\hline Randıman & 90 & 91 & 90 & 93 & 91 & 87 & 88 \\
\hline Üretim Miktarı (kg) & 677.4 & 685.0 & 677.4 & 700.0 & 685.0 & 654.9 & 662.4 \\
\hline
\end{tabular}

Tablo 5' de görüldüğü üzere Büküm(T/M) makinede akan şerite bir metre boyunca Atılacak tur sayısınıi Ne şerit (iplik oluşması için kalın pamuk yığını) numarasını, devir makinenin dakika' da ki dönüş hızına bağlı olarak üretilen şeritin metre miktarını, randıman ise gerçekleşen verimlilik oranını (olması gereken randıman oranı \%93), üretim miktarı ise fiili üretim miktarını göstermektedir. Tabloda verilen teknik değerler işletmenin çalışması esnasında ki makinelerin verisidir. Gerçekleşen üretim miktarı ise Microsoft Excel yardımıyla hesaplanmış olup Ring 1 sütunu aşağıya doğru B2 (20) - B3 (678) - B4 (10000) - B5 (90) gerçekleşen randıman - B6 $(677,4)$ hücresel olarak sınıflandırılacak olursa B6 olan hücre yani üretim miktarı bu şekilde $=(1200 *((\mathrm{~B} 5 / \mathrm{B} 4) /(1,693 * \mathrm{~B} 3)) *(\mathrm{~B} 6 / 100) * 60 * 24) / 1000$ formülüze edilerek $677,4 \mathrm{~kg}$ üretim miktarı bulunmuştur. Diğer üretim hesaplamaları hücresel olarak sınıflandırılarak üretim miktarı bu şekilde hesaplanmıştır.

Ring makineleri direk Fitil ünitesinden beslendiği için tüm makinelerin toplam üretimine bakarak üretim planlamasının yapılması için Microsoft Excel yardımıyla hesaplanmış olan ve =EĞER(TOPLA(B5:S5)<9800.3;"Üretimi Artır"; "Üretim Bu Şekilde Devam Etsin") bu şekilde formülüze edilen karar destek sistemiyle yöneticilerin karar vermelerine yardımcı olacaktır. 9800.3 rakamı referans randıman oranı $\% 93$ baz alınarak belirlenmiştir. $9439<9800.3$ olduğundan üretimin artırılması yönünde karar alınabilir.

Tablo 6. Bobin Makinesi Üretim Verileri

\begin{tabular}{|c|c|c|c|c|c|}
\hline Makine Bilgileri & Bobin 1 & Bobin 2 & Bobin 3 & Bobin 4 & Bobin 5 \\
\hline Ne & 20 & 20 & 20 & 20 & 20 \\
\hline Devir(m/dk) & 890 & 890 & 890 & 890 & 890 \\
\hline Randıman & 82 & 80 & 79 & 81 & 82 \\
\hline Üretim Miktarı (kg) & 1.862 .2 & 1.816 .8 & 1.794 .1 & 1.839 .5 & 1.862 .2 \\
\hline
\end{tabular}

Tablo 6' da görüldüğü üzere Ne şerit (iplik oluşması için kalın pamuk yığını) numarasını, devir makinenin dakika' da ki dönüş hızına bağlı olarak üretilen şeritin metre miktarını, randıman ise gerçekleşen verimlilik oranını (olması gereken randıman oranı \%83), üretim miktarı ise fiili üretim miktarını göstermektedir. Tabloda verilen teknik değerler işletmenin çalışması esnasında ki makinelerin verisidir. Gerçekleşen üretim miktarı ise Microsoft Excel yardımıyla hesaplanmış olup Bobin 1 sütunu aşağıya doğru B2 (20) - B3 (890) - B4 (72) gerçekleşen randıman - B5 $(1862,2)$ hücresel olarak sınıflandırılacak olursa B5 olan hücre yani üretim miktarı bu şekilde $=((\mathrm{B} 4 /(1.693 * \mathrm{~B} 3)) *(\mathrm{~B} 5 / 100) * 60 * 60 * 24) / 1000$ formülüze 204 
edilerek 1862,2 kg üretim miktarı bulunmuştur. Diğer üretim hesaplamaları hücresel olarak sınıflandırılarak üretim miktarı bu şekilde hesaplanmıştır.

Bobin makineleri direk Ring ünitesinden beslendiği için tüm makinelerin toplam üretimine bakarak üretim planlamasının yapılması için Microsoft Excel yardımıyla hesaplanmış olan ve =EĞER(TOPLA(B5:F5)<9424,6;"Üretimi Artır"; "Üretim Bu Şekilde Devam Etsin") bu şekilde formülüze edilen karar destek sistemiyle yöneticilerin karar vermelerine yardımcı olacaktır. 9424,6 rakamı referans randıman oranı \%83 baz alınarak belirlenmiştir. $9174,8<9424,6$ olduğundan üretimin artırılması yönünde karar alınabilir.

Tablo 7. Ambalaj Bölümü Operatörleri Verileri

\begin{tabular}{|c|c|c|c|c|c|}
\hline Operatör Bilgileri & $\begin{array}{c}\mathbf{1 .} \\
\text { Operatör }\end{array}$ & $\begin{array}{c}\mathbf{2 .} \\
\text { Operatör }\end{array}$ & 3. Operatör & $\begin{array}{c}\mathbf{4 .} \\
\text { Operatör }\end{array}$ & $\begin{array}{c}5 . \\
\text { Operatör }\end{array}$ \\
\hline $\begin{array}{c}\text { Planlanan Çuval } \\
\text { Adet Sayısı }\end{array}$ & 33 & 33 & 33 & 33 & 33 \\
\hline Ortalama Çuval Ağırlı̆ıı & 56.4 & 57.3 & 54.9 & 55.7 & 55.6 \\
\hline Üretim Miktarı (kg) & 1861.2 & 1890.9 & 1811.7 & 1838.1 & 1834.8 \\
\hline
\end{tabular}

Tablo 7' de görüldüğü üzere planlanan çuval âdeti sayısı operatörün yapması gereken çuval âdetini, üretim miktarı ise çuvallanıp tartılan fiili üretim miktarını göstermektedir. Tabloda verilen teknik değerler işletmenin çalışması esnasındaki yönetimin belirlediği referans değerlerdir. Gerçekleşen üretim miktarı ise Microsoft Excel yardımıyla hesaplanmış olup 1. Operatör sütunu aşağıya doğru B2 (33) - B3 (56,5) - B4 (1862.7) hücresel olarak sinıflandırılacak olursa B4 olan hücre yani üretim miktarı bu şekilde $=\mathrm{B} 2 * \mathrm{~B} 3$ formülüze edilerek $1862,7 \mathrm{~kg}$ üretim miktarı bulunmuştur. Diğer üretim hesaplamaları hücresel olarak sınıflandırılarak üretim miktarı hesaplanmıştır.

Ambalaj bölümü direk Bobin ünitesinden beslendiği için tüm makinelerin toplam üretimine bakarak üretim planlamasının yapılması için Microsoft Excel yardımıyla hesaplanmış olan ve =EĞER(TOPLA(B5:F5)<9570;"Üretimi Artır"; "Üretim Bu Şekilde Devam Etsin") bu şekilde formülüze edilen karar destek sistemiyle yöneticilerin karar vermelerine yardımcı olacaktır. 9570 rakamı 24 saat içinde yapılması gereken çuval âdeti (Bir çuval $58 \mathrm{~kg}$ ) 33 adet baz alınarak belirlenmiştir. 9237<9570 olduğundan üretimin artırılması yönünde karar alınabilir.

Araştırma sonuçları baz alınarak oluşturulan üretim planlaması kararları işletmenin iyi bir noktaya varabilmesi için nasıl ve neler yapılması gerektiği araştırılmıştır. Araştırmadan elde edilen sonuçlat tablo 8' de görülmektedir.

Tablo 8. Üretim Planlaması İçin Karar Destek Sistemi Önerilerinin Yazılımsal Formülasyonu

\begin{tabular}{|c|c|c|c|}
\hline Makine & $\begin{array}{c}\text { Hesap ve } \\
\text { Üretim } \\
\text { Planlaması } \\
\text { Karar } \\
\text { Önerisi }\end{array}$ & Karar Önerisi Yazılımsal Formülüzasyonu & $\begin{array}{c}\text { Üretim Planlaması için } \\
\text { Önerisi }\end{array}$ \\
\hline Tarak & Üretim & $(((\mathrm{B} 3 * 60) /(1.693 * \mathrm{~B} 2)) *(\mathrm{~B} 4 / 100)) / 1000) * 24$ & Üretimi \\
\hline
\end{tabular}


DULKADİR

\begin{tabular}{|c|c|c|c|}
\hline & Hesabı & & \multirow[t]{2}{*}{ Artır } \\
\hline & $\begin{array}{l}\text { Karar } \\
\text { Önerisi }\end{array}$ & $\begin{array}{c}=\text { EĞER(TOPLA(B5:M5)<10773.8;"Üretimi Artır"; "Üretim } \\
\text { Bu Şekilde Devam Etsin") }\end{array}$ & \\
\hline \multirow{2}{*}{$\begin{array}{l}\text { Cer1 } \\
\text { I.Pasaj }\end{array}$} & $\begin{array}{l}\text { Üretim } \\
\text { Hesabı }\end{array}$ & $((((\mathrm{B} 4 * 60) /(1.693 * \mathrm{~B} 3)) *(\mathrm{~B} 5 / 100)) / 1000) * 24$ & \multirow{2}{*}{$\begin{array}{l}\text { Üretimi } \\
\text { Artır }\end{array}$} \\
\hline & $\begin{array}{l}\text { Karar } \\
\text { Önerisi }\end{array}$ & $\begin{array}{c}=\text { EĞER(TOPLA(B5:D5)<10599.3;"Üretimi Artır"; "Üretim } \\
\text { Bu Şekilde Devam Etsin") }\end{array}$ & \\
\hline \multirow{2}{*}{$\begin{array}{l}\text { Cer1 } \\
\text { II.Pasaj }\end{array}$} & $\begin{array}{l}\text { Üretim } \\
\text { Hesabı }\end{array}$ & $((((\mathrm{B} 4 * 60) /(1.693 * \mathrm{~B} 3)) *(\mathrm{~B} 5 / 100)) / 1000) * 24$ & \multirow{2}{*}{$\begin{array}{l}\text { Üretimi } \\
\text { Artır }\end{array}$} \\
\hline & $\begin{array}{l}\text { Karar } \\
\text { Önerisi }\end{array}$ & $\begin{array}{c}=\text { EĞER(TOPLA(B5:D5)<10599.3;"Üretimi Artır"; "Üretim } \\
\text { Bu Şekilde Devam Etsin") }\end{array}$ & \\
\hline \multirow{2}{*}{ Fitil } & $\begin{array}{l}\text { Üretim } \\
\text { Hesabı }\end{array}$ & $(120 *((\mathrm{~B} 5 / \mathrm{B} 4) /(1.693 * \mathrm{~B} 3)) *(\mathrm{~B} 6 / 100) * 60 * 24) / 1000$ & \multirow{2}{*}{$\begin{array}{l}\text { Üretimi } \\
\text { Artır }\end{array}$} \\
\hline & $\begin{array}{l}\text { Karar } \\
\text { Önerisi }\end{array}$ & $\begin{array}{c}=\text { EĞER(TOPLA(B5:E5)<9984.8;"Üretimi Artır"; "Üretim } \\
\text { Bu Şekilde Devam Etsin") }\end{array}$ & \\
\hline \multirow{2}{*}{ Ring } & $\begin{array}{l}\text { Üretim } \\
\text { Hesabı }\end{array}$ & $(1200 *((\mathrm{~B} 5 / \mathrm{B} 4) /(1.693 * \mathrm{~B} 3)) *(\mathrm{~B} 6 / 100) * 60 * 24) / 1000$ & \multirow{2}{*}{$\begin{array}{l}\text { Üretimi } \\
\text { Artır }\end{array}$} \\
\hline & $\begin{array}{l}\text { Karar } \\
\text { Önerisi }\end{array}$ & $\begin{array}{c}=\text { EĞER(TOPLA(B5:S5)<9800.3;"Üretimi Artır"; "Üretim } \\
\text { Bu Şekilde Devam Etsin") }\end{array}$ & \\
\hline \multirow{2}{*}{ Bobin } & $\begin{array}{l}\text { Üretim } \\
\text { Hesabı }\end{array}$ & $((\mathrm{B} 4 /(1.693 * \mathrm{~B} 3)) *(\mathrm{~B} 5 / 100) * 60 * 60 * 24) / 1000$ & \multirow{2}{*}{$\begin{array}{l}\text { Üretimi } \\
\text { Artır }\end{array}$} \\
\hline & $\begin{array}{l}\text { Karar } \\
\text { Önerisi }\end{array}$ & $\begin{array}{c}=\text { EĞER(TOPLA(B5:F5)<9424.6;"Üretimi Artır"; "Üretim } \\
\text { Bu Şekilde Devam Etsin") }\end{array}$ & \\
\hline \multirow{2}{*}{ Ambalaj } & $\begin{array}{l}\text { Üretim } \\
\text { Hesabı }\end{array}$ & $\mathrm{B} 2 * \mathrm{~B} 3$ & \multirow{2}{*}{$\begin{array}{l}\text { Üretimi } \\
\text { Artır }\end{array}$} \\
\hline & $\begin{array}{l}\text { Karar } \\
\text { Önerisi }\end{array}$ & $\begin{array}{c}=\text { EĞER(TOPLA(B5:F5)<9570;"Üretimi Artır"; "Üretim Bu } \\
\text { Şekilde Devam Etsin") }\end{array}$ & \\
\hline
\end{tabular}

Tablo 8' de Ring iplik işletmesinin tüm makine parkları, üretim hesabının formülü ve karar önerisinin yazılımsal formülü, formüllerin açılımları ve gerçekleşen üretim miktarına göre karar önerisi görülmektedir. Üretimi artır karar önerisi ile İşletmedeki tüm makinelerde randıman kaybı olduğu görülmektedir. Sonuç olarak ortaya çıkan üretim kaybının azaltılması önem taşımaktadır. Bu şekilde geliştirilen bir model tüm sektörler için örnek teşkil edebilecektir. Karar destek sistemi yardımıyla kayıplar azaltılabilecektir. Üretimdeki kayıplar çeşitli nedenlerden kaynaklanabilir. Bu kayıpların nedenleri ise malzeme kalitesi kaynaklı, üretim ölçme (kalite kontrol) yöntemleri, makine-teçhizat ve Enerji ile ilgili etkenler, İstenilen kalitenin dışındaki ürünler, planlı duruşların eksikliği ya da fazlalılığı, insan unsuru, vardiya değişimlerindeki kayıplar, ücret durumu gibi birçok etkenden kaynaklanabilir. Sorunun neden ve nasıl kaynaklandığı yöneticilerce tespit edilerek buna göre karar verilmelidir. Her makine ayrıntılı olarak detaylı olarak incelenmelidir. Olumsuz görülen ve görülebilecek durumlar gözden geçirilmelidir. Çünkü üretim kaybı maliyet işletme için ise zarar demektir. 


\section{SONUÇ VE ÖNERILLER}

İş dünyasında kalite, zaman ve maliyet işletmenin yönetimi için ciddi önem taşımakta olup bunlara artık günümüzde bilişim teknolojisi kullanımı da eklenmiştir. İşletmelerin rekabet ortamında diğer işletmelere göre üstünlük kazanması için bunlar artık anahtar kelimeler olmuş olup, bilişim teknolojisi unsurlarından olan karar destek sistemleri de bu önemli unsurlardan birisidir. Karar destek sistemleri yöneticiler için gerekli olan bilgilerin düzenlenmesi, diğer işletme bilgileri ile ilişkilendirilmesi, alternatifler ile farklı çözümler bulunarak hızlı ve doğru karar alınmasında yöneticilere yardım eden bilişim tabanlı bir sistemdir. İşletmelerde yöneticilerin hızlı ve doğru kararlar alması önem taşımakta olup bunun için bilgilerin güncel bir şekilde en doğru kaynaklardan alınarak yöneticilerce kullanılmalıdır. Kararların kullanıldığı konulardan birisi ise üretim işletmelerinde üretim planlanması ve dolayısıyla üretim yönetimi faaliyetleridir. Üretim yönetimi faaliyetleri için üretim planlaması yapılırken karar destek sistemlerinden de yararlanılmaktadır. İşletmelerde üretim faaliyetleri devam ederken ya da planlanırken işletmenin durumuna göre planlama faaliyetleri değişkenlik gösterebilir. Bu değişkenliklerde yöneticiler bilişim teknolojisinin unsurlarından olan karar destek sistemlerinden faydalanarak en doğru kararları vermeye çalışmaktadır.

Yapılan araştırmada bilişim teknolojisi tabanlı karar destek sistemlerinden olan Microsoft Excel programı yardımıyla üretimin verimli bir şekilde devam etmesi için iplik üretiminin planlanması konusunda yöneticilerin karar vermesinde etkililiğini artırmak amaçlanmıştır. Microsoft Excel kullanılarak çeşitli üretim hesaplamaları yapılmıştır. Yöneticilerin üretim planlaması konusunda karar vermelerine yardımcı olmasına yarayan bilişim teknolojisi tabanlı olan bu sistemden en yüksek seviyede yararlanması amaçlanmıştır. İşletmenin 24 saat' lik üretimi dikkate alınmıştır. Referans üretim miktarları ve gerçekleşen üretim miktarları arasında karar destek sistemleri yardımıyla üretimin planlanması açısından bağlantılar kurulmasına çalışılmışıı. Araştırmada Microsoft Excel programı yardımıyla her makine kendinden bir önceki makinenin yarı mamul beslemesi durumu için üretim artırılsın, üretim aynı kalsın şeklinde karar önerilerinde bulunacak şekilde formülüze edilmiştir. Üretim esnasında bazı nedenlerden kaynaklı duruşlar olmuştur. Böylece yöneticiler tarafindan üretim planlaması ile ilgili geleceğe yönelik kararlar alınması konusunda bu bilgilerden yararlanılabilecektir.

Üretim planlaması için kurulan bu karar destek sistemi işletmenin tüm birimleri ve işlemleri için uygulanmalıdır. Sistem işletme yöneticilerinin durumu analiz edip karar vermelerine yardımcı olabilecektir. Böylece üretimin planlanması için karar verme konusunda yöneticilere fayda sağlayacaktır. Çünkü karar verilme noktasında bu sistemler yöneticilere yol gösterecek olup en küçük kayıp bile önlenilmeye çalışılacaktır. Çünkü en küçük bir üretim kaybı işletme için maliyet kaybıdır. Üretim kaybı ve nasıl önlem alınacağı tüm çalışanlara ciddi bir şekilde aşılanmalıdır. Kayıpların yaşanmaması için işletmede gerekli çalışmalar yapılmalı ve bu kayıpların önüne geçilmelidir. İşletme yöneticileri; çalışanların eğitimi, makine, malzeme, ortamın fiziksel şartları vb. durumların sürekli takibini yaparak, iş ve zaman etüdü tekniğiyle iş kaybını en aza indirmelidir. Sonuç olarak üretim kaybı tüm işletmeyi ilgilendiren bir maliyet kaybidır.

\section{KAYNAKÇA}


ALAGÖZ, A., ÖĞE, S., \& KOÇYİ̆̈IT, N. (2013). "Muhasebe Bilgi Sistemi ve Karar Destek Sistemleri İlişkisinin Yönetsel Karar Alma Faaliyetlerine Etkisi”, Selçuk Üniversitesi Sosyal Bilimler Enstitüsü Dergisi, (30), 27-40.

ARSLAN, M. (2019). Depo Yönetiminde Karar Destek Sistemleri Kullanımı Ve Ürün Yerleşiminde Önemli Olan Kriterlerin Belirlenmesi Üzerine Bir Uygulama, (Yüksek Lisans Tezi). Maltepe Üniversitesi Sosyal Bilimler Enstitüsü, İstanbul.

BENSGHIR, T. K. (1996). Bilgi Teknolojileri ve Örgütsel Değişim, Ankara: Türkiye ve Orta Doğu Amme İdaresi Enstitüsü.

DEMİR, E., DİNÇER, S. E. (2020). "Üretim Sektöründe Veri Madenciliği Uygulamaları: Literatür Taraması", Anadolu Üniversitesi İşletme Fakültesi Dergisi (İŞFAD), 2 (1): $1-12$.

DEMİRDÖĞEN, O. \& GÜZEL, D. (2009). “Üretim Planlama Ve İş Yükleme Metotları", Atatürk Üniversitesi İktisadi ve İdari Bilimler Dergisi, 23(4), 43-67.

DÖNERÇARK, M. (2020). Kurumsal Karar Destek Sistemlerinde Yapay Zekâ Kullanımı: Tasarım Ve Uygulama,. (Yayımlanmamış Yüksek Lisans Tezi). Dokuz Eylül Üniversitesi, Sosyal Bilimler Enstitüsü Yönetim Bilişim Sistemleri Anabilim Dalı, İzmir

GÖKŞEN, Y., AŞAN, H. \& DAMAR, M. (2015). “İşücü Planlamasında Bir Karar Destek Sistemi Uygulaması”, Dokuz Eylül Üniversitesi Sosyal Bilimler Enstitüsü Dergisi, 17(1), 53-66.

GRAVES, S. (1999). Manufacturing Planning And Control, Massachusetts Institute of Technology.

GÜNGÖR, Ş. C. \& CENKÇİ, D. (2009). "Üretim Planlama Performans Ölçütlerinin Belirlenmesi ve Değerlendirilmesine Entegre Bir Yaklaşım”, Mühendislik ve Fen Bilimleri Dergisi, (27), 1-17.

KARAÖZ, B. (2014). Maden Üretim Planlaması ve Çizelgelenmesi Üzerine Bir Tam Sayılı Programlama Önerisi: Kar Maden Örneği, (Yayımlanmamış Yüksek Lisans Tezi). Hacettepe Üniversitesi Sosyal Bilimler Enstitüsü İşletme Anabilim Dalı Üretim Yönetimi ve Sayısal Yöntemler Programı, Ankara.

LAUDON, K., \& LAUDON, J. (2018). Management Information Systems 'Managing the Digital Firm' Fifteenth Edition. Pearson Education Limited.

LIANG, T. P. \& SHIN, Y. H. (1997). "DSS and EIS Applications in Taiwan" Information Technology \& People, 11(4), 303-315.

MCLEOD, R. J. (1995). Management Information Systems A study af Computer-Based Information Systems, Prentice Hall International, New Jersey

PAKSOY, T. \& ATAK, M. (2003). "Etkileşimli Bulanık Çok Amaçlı Doğrusal Programlama ile Bütünleşik Üretim Planlama”, Gazi Üniversitesi Fen Bilimleri Enstitüsü Dergisi, 15(2), 457-466.

SIMON, A.H. (1960). The New Science Of Management Decision, Harper, Newyork. 
SINDIR, K. O. (2006) "Yönetim ve Karar Destek Sistemleri”, (Çeviren: Öztekin, Tekin) Farm and Crop Management Systems, (6), 355-367

SOMAN, C,. ANILI D., DIRK, P. \& GAALMAN, D. G. (2004). "Combined Make-ToOrder and Make-To-Stock in a Food Production System", International Journal of Production Economics, 90(2), 223-235.

ÖZER, B. \& KUŞLU, M. (2012). "Yerel Yönetimlerdeki Yönetim Bilgi Sistemleri ve Karar Destek Süreçleri: Manisa Belediyesi Örneği”, Celal Bayar Üniversitesi Sosyal Bilimler Dergisi, 10(1), 389-410.

UMEROVA, L. (2019). Uçak Motorları Bakım Onarım Süreçleri İçin Optimal Karar Destek Sistemleri Geliştirilmesi, (Yüksek Lisans Tezi). Yıldız Teknik Üniversitesi Fen Bilimleri Enstitüsü, İstanbul.

WATKINS. D. J. \& MCKINNEY. D. (1995). Recent Developments Associated With Decision Support Systems İn Water Resources . Rev. Geophysics. 